\title{
Accelerated Weatherability of the Low-Density Polyethylene Nanocomposites with Silica, Clay, and Zinc Oxide
}

\author{
Halim Hamid Redhwi, ${ }^{1}$ Mohammad Nahid Siddiqui, ${ }^{2}$ \\ Anthony L. Andrady, ${ }^{3}$ and Syed Hussain ${ }^{4}$ \\ ${ }^{1}$ Chemical Engineering Department, King Fahd University of Petroleum \& Minerals, Dhahran 31261, Saudi Arabia \\ ${ }^{2}$ Chemistry Department and Center of Excellence in Nanotechnology (CENT), King Fahd University of Petroleum \& Minerals, \\ Dhahran 31261, Saudi Arabia \\ ${ }^{3}$ Department of Chemical and Biomolecular Engineering, North Carolina State University, Raleigh, NC 27607, USA \\ ${ }^{4}$ Dhahran Techno-Valley, King Fahd University of Petroleum \& Minerals, Dhahran 31261, Saudi Arabia
}

Correspondence should be addressed to Syed Hussain; syedhussain@kfupm.edu.sa

Received 22 June 2014; Revised 21 August 2014; Accepted 15 September 2014; Published 13 October 2014

Academic Editor: Shiren Wang

Copyright (C) 2014 Halim Hamid Redhwi et al. This is an open access article distributed under the Creative Commons Attribution License, which permits unrestricted use, distribution, and reproduction in any medium, provided the original work is properly cited.

Nanocomposites based on low-density polyethylene (LDPE) with MMT clay, nanosilica, and nanoscale zinc oxide (at 5 wt.\%) were prepared by melt processing and evaluated for durability using laboratory accelerated weathering. The changes in tensile properties of the nanocomposites with the duration of exposure were compared to data from natural weathering outdoors. The enhancement of degradation rates of the LDPE matrix by the presence of nanofillers in accelerated weathering is reported.

\section{Introduction}

The global market for thermoplastic composites has been growing rapidly in the past decade; the value of these products well exceeds even that of thermosets. Though composites account for less than $5 \%$ of the global consumption their growth rate is estimated to be $5 \%$ globally until 2018 creating a market of USD6.2 billion [1]. Using nanocomposites in transportation and building applications is a recent phenomenon that is very likely to create substantial market opportunity.

Provided good compatibility between the plastic matrix and the nanoscale filler exists their high specific area should allow high reinforcement to be achieved at considerably lower volume fractions of filler. The level of reinforcement obtained depends on the hierarchical microstructure of the filler within the matrix. Ensuring the high levels of dispersion that is needed to derive high levels of reinforcement from nanoparticles is often difficult to achieve [2]. Surface treatment of the nanoparticles is often resorted to increase compatibility with matrix and obtain the best results. Translating laboratory techniques that deliver very good dispersion and exfoliation, such as in situ polymerization or solvent-based mixing is not practical on an industrial scale. Techniques that deliver high dispersion in melt mixing using conventional process equipment are critical to success of nanocomposites.

An important side effect if incorporating nanofillers into a matrix is the modification of the light-stability due to increased specific light shielding obtained with nanofillers over the conventional fillers. In general, the expectation is that this would enhance the photostability of the plastic [3] provided the nanofiller material itself is not photocatalytic. This has been demonstrated in some nanocomposites at laboratory scale; other systems, however have shown lowered photostability due to the presence of the nanofiller. la Mantia et al. [4] and others $[5,6]$ showed that the photostability of LDPE/clay nanocomposites is lower than that for the unfilled polymer. We have reported the relative efficiencies of reinforcement of LDPE matrices by montmorillonite clay, zinc oxide, and silica and the impact of the filler on photostability of the polymer in outdoor exposure under desert exposure conditions. 
TABLE 1: Summary of nanocomposite characteristics.

\begin{tabular}{lcccccc}
\hline Filler & Density $(\mathrm{g} / \mathrm{cc})$ & Filler $V_{f}$ & $\Delta$ Modulus $/ V_{f} \mathrm{MPa}$ & $M / M_{o}$ & Nominal BET values (sq.m./g) & Primary particle size (nm) \\
\hline Closite & 2.86 & 0.027 & 1992 & 2.54 & 750 & See below \\
Zinc Oxide & 5.6 & 0.009 & 981 & 2.52 & 35 & 30 \\
Silica & 2.1 & 0.023 & 2369 & 1.25 & $\sim 50$ & 40 \\
\hline
\end{tabular}

In this continuation of the work we report findings from accelerated laboratory exposure of the same set of nanocomposites (see Table 1), comparing outdoor and accelerated test data. We further explore what the data suggests in terms of the reciprocity of exposure for these three thermoplastic nanocomposite materials. Knowledge of their reciprocity is important in extrapolating weatherability data derived from one set of exposure conditions to others where the intensity of light available might be different. The temperature differences between locations are usually taken into account using the Arrhenius model.

\section{Experimental}

MMT Clay-Cloisite 20A (Nanocor, Hoffman Estates, IL); zinc oxide (Advanced Materials, Manchester, CT); nanosilica Aerosil OX 50 (Evonik, Addison, IL); Cloisite 20, montmorillonite clay modified with a quaternary ammonium salt, were all used as received. Melt mixing of these with the injectionmoldable grade LDPE was carried out in a Theyson TSK $21 \mathrm{~mm}$ Twin Screw extruder. The screw rpm was controlled at 215-218 during extrusion and the melt temperature was maintained in the range of $375 \mathrm{~F}$ to $401 \mathrm{~F}\left(190\right.$ to $\left.205^{\circ} \mathrm{C}\right)$. The compounded resin with $5 \mathrm{wt} \%$ of nanofiller was pelletized and stored dry. Injection molding of the ASTM Type I test pieces was carried out on a 165 ton Engel Machine at a nozzle temperature of $420 \mathrm{~F}\left(215^{\circ} \mathrm{C}\right)$ and an injection pressure of 5000 psi. Test pieces were stored in the dark at ambient temperature until testing and/or exposure experiments. Properties of the fillers are summarized in Table 1.

Tensile testing was done according to ASTM D 638 using an Instron Tensile Testing machine, Model 3367. Testing was carried out at a strain rate of $10 \mathrm{~mm} / \mathrm{min}$. Load displacement data was recorded digitally for six replicates.

Weatherometer experimental testing was carried out in Q-SUN Xenon test chambers model Q-Sun (Xe-3) at an irradiance of $0.4 \mathrm{~W} / \mathrm{m}^{2} / \mathrm{nm}$ and $340 \mathrm{~nm}$ wavelength using daylight filter with continuous illumination at 70 degrees Celsius chamber air temperature. Other factors such as humidity and atmospheric pollutants can affect the rate of weathering of polymers outdoors. However, the solar UV radiation is the predominant factor and used as the sole weathering agent in the present study.

Concentrated sunlight exposures were carried out in a QTRAC device located in Phoenix, AZ. The device uses an array of 10 mirrors that automatically tracks the sun throughout the day in both azimuth (horizontally) and elevation (vertically). This maximizes the full-spectrum light energy received by the sample. The test was carried out without using any water spray but the sample temperature was maintained $\sim 70$ degrees Celsius throughout the exposure.

The particle size of the filler is clearly an important variable; the smaller the average particle size is, the larger the specific surface area will be and hence the higher the interface available with the matrix, leading to better reinforcement. With Closite, the agglomerate size was 8 microns but the thickness of the exfoliated particle was $\sim 1 \mathrm{~nm}$. The clay is modified with $\mathbf{N}, \mathbf{N}$-dimethyl dihydrogenated tallow quaternary ammonium chloride, at a concentration that is 95 m.equiv/100 g.

\section{Results and Discussions}

3.1. Accelerated Weathering Results. As shown in Table 2, the weatherometer exposure resulted in rapid degradation of the LDPE/MMT nanocomposites compared to unfilled polymer, at all three dosages. This observation is consistent with previous reports Huaili et al. [7], Qin et al. [6], la Mantia et al. [4] and Dintcheva et al. [8] for accelerated weathering of LDPE/MMT nanocomposites. Acceleration in degradation was attributed to the presence of $\mathrm{NH}_{4}+$ ions derived from the organic modifier of MMT by Qin et al. [6] and to the catalytic activity of trace metal ions in clay, by la Mantia et al. [4]. Metal ions catalyze hydroperoxide decomposition and can reduce the induction time for the photooxidation reactions. The result is therefore not surprising and it is our previously outdoor weathering data [9] that appears to be inconsistent with the literature. In this study unstabilized LDPE was used and the changes in mechanical properties with exposure were faster compared to light-stabilized LDPE reported by others [10].

The same is true of the LDPE/Silica nanocomposites. In this case, however, the data from accelerated weathering is qualitatively consistent with that from outdoor weathering as well. In both studies the presence of nanosilica reduced the photostability of LDPE. Silica powder was reported to be a prooxidant in low molecular weight hydroxyl-terminated polyethylenes [11]. They too are believed to catalyze the peroxide decomposition step during autoxidation. Silica also promotes free-radical production in biological systems [12].

The behavior of the LDPE/ZnO nanocomposite in the present study is unexpected and is inconsistent with the data from outdoor exposure study. In $\mathrm{PP} / \mathrm{ZnO}$ nanocomposites, for instance, up to $5 \mathrm{wt} \%$ of $\mathrm{ZnO}$ was reported to stabilize polypropylene, a relatively more photolabile polymer compared to LDPE [13]. Light shielding by $\mathrm{ZnO}$ surface coatings was demonstrated to stabilize polycarbonate laminates [14]. 
TABLE 2: Tensile test results for accelerated weathering in the laboratory of LDPE based nanocomposites.

\begin{tabular}{|c|c|c|c|c|c|c|c|c|c|}
\hline $\begin{array}{l}\text { Energy } \\
\mathrm{kJ} / \mathrm{sq} \cdot \mathrm{m} \\
\text { measured at } \\
340 \mathrm{~nm}\end{array}$ & $\begin{array}{l}\text { Eq. } \\
\text { outdoor } \\
\text { exposure } \\
\text { (months) }\end{array}$ & $\begin{array}{l}\mathrm{LDPE} \\
E(\%)\end{array}$ & $\begin{array}{l}\text { LDPE } \\
\text { T.S } \\
(\mathrm{MPa})\end{array}$ & $\begin{array}{l}\text { Clay } \\
\text { filler } \\
E(\%)\end{array}$ & $\begin{array}{l}\text { Clay filler } \\
\text { T.S (MPa) }\end{array}$ & $\begin{array}{c}\mathrm{ZnO} \text { filler } \\
E(\%)\end{array}$ & $\begin{array}{l}\mathrm{ZnO} \text { filler } \\
\mathrm{T} . \mathrm{S}(\mathrm{MPa})\end{array}$ & $\begin{array}{c}\mathrm{SiO}_{2} \text { filler } \\
E(\%)\end{array}$ & $\begin{array}{l}\mathrm{SiO}_{2} \text { filler } \\
\mathrm{T} . \mathrm{S}(\mathrm{MPa})\end{array}$ \\
\hline 0 & & 172.12 & 10.21 & 169 & 10.21 & 159.47 & 10.54 & 153.86 & 10.74 \\
\hline 1456.2 & 2.05 & 54.01 & 6.37 & 35.51 & 5.83 & 3.38 & 2.04 & 41.00 & 6.11 \\
\hline 2087.7 & 2.93 & 46.12 & 6.53 & 16.93 & 3.99 & - & - & 31.97 & 6.01 \\
\hline 3037.8 & 4.27 & 34.96 & 6.08 & 6.97 & 1.68 & - & - & 21.03 & 5.21 \\
\hline
\end{tabular}

3.2. Comparison of Natural and Accelerated Exposures. The total UV dose of exposure in the weatherometer experiments was fixed at three levels. These radiation doses can be converted into approximately equivalent durations of outdoor exposure (see Table 2) using published solar UV data for Saudi Arabia. The 10-yr average insolation in Dhahran (Saudi Arabia) is known to be $6.03 \mathrm{MJ} / \mathrm{sq} . \mathrm{m} . /$ day. The spectral irradiance distribution in both cases is the same as a filtered xenon source was used in the weatherometer.

The ultimate extensibility data for samples exposed in the weatherometer, however, show values obtained at much longer durations compared to the equivalent durations based in UV dose. The outdoor exposure data already reported in part II of this series might be used to estimate the duration at which these values of extensibility might be expected. Interpolation of plots of the extensibility versus outdoor exposure duration allows these to be estimated. Table 3 shows a wide disparity between the two estimates.

Clearly, the outdoor and laboratory-accelerated weathering environments obtained different weathering regimes. Weatherometer environment differed from outdoor exposure in two important respects: (a) the temperature was maintained at 70 degrees Celsius with no cycling; (b) the irradiation was continuous with no light/dark cycles.

The temperature effect on weathering degradation is well known and is often modeled using the Arrhenius equation. In the weatherometer exposures, the temperature was maintained continuously at 70 degrees Celsius while the outdoor samples experienced temperature cycling. As these were at a much lower temperature for over half the duration of exposure, the higher rate of degradation in the weatherometer exposure is to be expected.

\subsection{Irradiance and Dose Rate Effects (Reciprocity Rule). As} an intermittent dark cycle was not used in the weatherometer exposure, the samples were continuously exposed to high-intensity of simulated sunlight. In the outdoor diurnal exposure cycle the high intensity comparable to that in the weatherometer is available only during the midday. While the total dose of radiation the sample was exposed to was about the same as the weatherometer exposures were at a higher intensity (and for a shorter time) compared to outdoor exposures.

Intensity-dependence of solar UV degradation of materials is generalized by the reciprocity rule [15] for the system. It says [16] that the photo-induced damage to materials depends on the source spectrum but is independent of the radiant intensity, $I$, and exposure time $t$. The law says

$$
I \cdot t=\text { constant }
$$

Not all polymers obey the rule; filled polymers are even less likely to do so because of the photoreactions involving the nanofiller.

The present observation that outdoor and accelerated weathering resulted in very different extents of degradation susggests that the reciprocity rule does not apply to the photodegradation of the LDPE nanocomposites investigated here. The lack of dark period $[17,18]$ in the exposure with no cycling and the higher continuous exposure temperature $[17,18]$ maintained throughout the exposure.

We have supplemented the data using exposures to concentrated sunlight in a Q-Trac concentrator in Phoenix, AZ (as shown in Table 4). These expsosures were at 70 degrees Celsius and delivered sunlight at $\sim 5-6$ times the normal intensity. The exposure duration was adjusted to be equivalent to 3 months of exposure at the Saudi Arabian exposure site in terms of the total dose of UV radiation. The tensile test data (Table 3 ) shows that the degradation obtained in this case is not as harsh as that in outdoor exposure. Our outdoor exposure of nanocomposite samples showed an extensibility of $100-130 \%$ after 3 months outdoors.

In this case as well the reciprocity rule does not hold for loss of tensile extensibility. The thermal exposure over the 3month period would have been much higher than that associated with about 1 month of concentrated exposure. Higher temperatures over a longer duration would have resulted in a harsher oxidative environment for the nanocomposite.

\section{Conclusions}

The degradation conditions in the accelerated weatherometer, outdoor exposure, and concentrated sunlight exposure used in this study were clearly very different despite the fact that the total UV dose in each case was about the same. The intensity of light, the rate of irradiation (with or without dark period), and temperature history of the different exposures are responsible for this difference. This observation suggests that for the loss in tensile extensibility of these types of nanocomposites the reciprocity rule of photodegradation does not hold. In designing weatherometer protocols the need 
TABLE 3: Comparison of outdoor exposure data with accelerated exposure data.

\begin{tabular}{lccc}
\hline $\begin{array}{l}\text { Dose-based equivalent } \\
\text { outdoor exposure (mos.) }\end{array}$ & Filler & $\begin{array}{c}\text { Observed elongation at } \\
\text { break (\%) }\end{array}$ & $\begin{array}{c}\text { Equivalent outdoor } \\
\text { exposure estimated from } \\
\text { extensibility data (mos.) }\end{array}$ \\
\hline 2.05 & Control & 54.01 & 7.8 \\
2.93 & & 46.12 & 8.1 \\
4.27 & MMT & 34.96 & 8.6 \\
\hline 2.05 & & 35.51 & 7.3 \\
2.93 & & 16.93 & 9.4 \\
4.27 & Silica & 6.97 & $>24$ months \\
\hline 2.05 & & 41.00 & 5.0 \\
2.93 & ZnO & 31.97 & 5.4 \\
4.27 & & 21.03 & 5.8 \\
\hline 2.05 & & 3.38 & $>24$ months \\
\hline
\end{tabular}

TABLE 4: Concentrated sunlight exposure (3 months outdoor exposure): average value (standard deviation).

\begin{tabular}{lccr}
\hline Samples & Maximum load, N & Tensile strength, MPa & Mean extensibility (\%) \\
\hline LDPE control & $363.23(1.84)$ & $9.46(0.10)$ & $160.75(3.89)$ \\
LDPE 5 wt\% ZnO & $374.16(2.35)$ & $9.72(0.07)$ & $147.98(2.99)$ \\
LDPE 5 wt\% silica & $387.49(2.91)$ & $10.09(0.09)$ & $140.63(3.90)$ \\
LDPE 5 wt\% clay & $368.64(1.41)$ & $9.61(0.07)$ & $150.44(3.33)$ \\
\hline
\end{tabular}

for temperature and light cycling should be considered as critical variables.

\section{Conflict of Interests}

The authors declare that there is no conflict of interests regarding the publication of this paper.

\section{Acknowledgment}

The authors would like to acknowledge the support provided by the Deanship of Scientific Research (DSR) at King Fahd University of Petroleum \& Minerals (KFUPM), Dhahran, Saudi Arabia, for funding this work through Project no. IN100021.

\section{References}

[1] Lucintel, Opportunities in Global Thermoplastic Composites Market 2009-2014: Trends, Forecast and Opportunity Analysis, Lucintel, Las Colinas, Tex, USA, 2013.

[2] S. C. Tjong, "Structural and mechanical properties of polymer nanocomposites," Materials Science and Engineering R: Reports, vol. 53, no. 3-4, pp. 73-197, 2006.

[3] J. Karger-Kocsis and S. Fakirov, Eds., Nano- and Micromechanics of Polymer Blends and Composites, pp. 425-470, chapter 12, Hanser, Munich, Germany, 2010.

[4] F. P. la Mantia, N. T. Dintcheva, V. Malatesta, and F. Pagani, "Improvement of photo-stability of LLDPE-based nanocomposites," Polymer Degradation and Stability, vol. 91, no. 12, pp. 3208-3213, 2006.

[5] S. Morlat-Therias, E. Fanton, J.-L. Gardette, N. T. Dintcheva, F. P. La Mantia, and V. Malatesta, "Photochemical stabilization of linear low-density polyethylene/clay nanocomposites: towards durable nanocomposites," Polymer Degradation and Stability, vol. 93, no. 10, pp. 1776-1780, 2008.

[6] H. Qin, Z. Zhang, M. Feng, F. Gong, S. Zhang, and M. Yang, "The influence of interlayer cations on the photooxidative degradation of polyethylene/montmorillonite composites," Journal of Polymer Science Part B: Polymer Physics, vol. 42, no. 16, pp. 3006-3012, 2004.

[7] Q. Huaili, Z. Chungui, Z. Shimin, C. Guangming, and Y. Mingshu, "Photo-oxidative degradation of polyethylene/montmorillonite nanocomposite," Polymer Degradation and Stability, vol. 81, no. 3, pp. 497-500, 2003.

[8] N. T. Dintcheva, S. Al-Malaika, and F. P. La Mantia, "Effect of extrusion and photo-oxidation on polyethylene/clay nanocomposites," Polymer Degradation and Stability, vol. 94, no. 9, pp. 1571-1588, 2009.

[9] H. H. Redhwi, M. N. Siddiqui, A. L. Andrady, and H. Syed, "Durability of LDPE nanocomposites with clay, silica, and zinc oxide II. weatherability of the nanocomposites," Polymer Composites, vol. 34, no. 11, pp. 1878-1883, 2013.

[10] S. M. Al-Salem, "Influence of natural and accelerated weathering on various formulations of linear low density polyethylene (LLPE) films," Materials and Design, vol. 30, no. 5, pp. 1729-1736, 2009.

[11] G. S. Olga, B. N. Sergey, V. S. Irina, V. A. Alexander, A. D. Jean, and G. P. Irina, "The study of influence of silica and polyethilene glycols organic-inorganic compounds on free-radical processes in vitro," Pharmacology \& Pharmacy, vol. 1, pp. 69-74, 2010.

[12] H.-M. Shen, Z. Zhang, Q.-F. Zhang, and C.-N. Ong, "Reactive oxygen species and caspase activation mediate silica-induced apoptosis in alveolar macrophages," American Journal of Physiology, vol. 280, no. 1, pp. L10-L17, 2001. 
[13] H. Zhao and R. K. Y. Li, "A study on the photo-degradation of zinc oxide $(\mathrm{ZnO})$ filled polypropylene nanocomposites," Polymer, vol. 47, no. 9, pp. 3207-3217, 2006.

[14] A. Moustaghfir, E. Tomasella, A. Rivaton et al., "Sputtered zinc oxide coatings: Structural study and application to the photoprotection of the polycarbonate," Surface and Coatings Technology, vol. 180-181, pp. 642-645, 2004.

[15] R. W. Bunsen and H. E. Roscoe, "Photochemische untersuchungen," Annalen der Physik, vol. 193, no. 12, pp. 529-562, 1863.

[16] J. W. Martin, J. W. Chin, and T. Nguyen, "Reciprocity law experiments in polymeric photodegradation: a critical review," Progress in Organic Coatings, vol. 47, no. 3-4, pp. 292-311, 2003.

[17] J. E. Pickett, D. A. Gibson, and M. M. Gardner, "Effects of irradiation conditions on the weathering of engineering thermoplastics," Polymer Degradation and Stability, vol. 93, no. 8, pp. 1597-1606, 2008.

[18] J. E. Pickett, D. A. Gibson, S. T. Rice, and M. M. Gardner, "Effects of temperature on the weathering of engineering thermoplastics," Polymer Degradation and Stability, vol. 93, no. 3, pp. 684-691, 2008. 

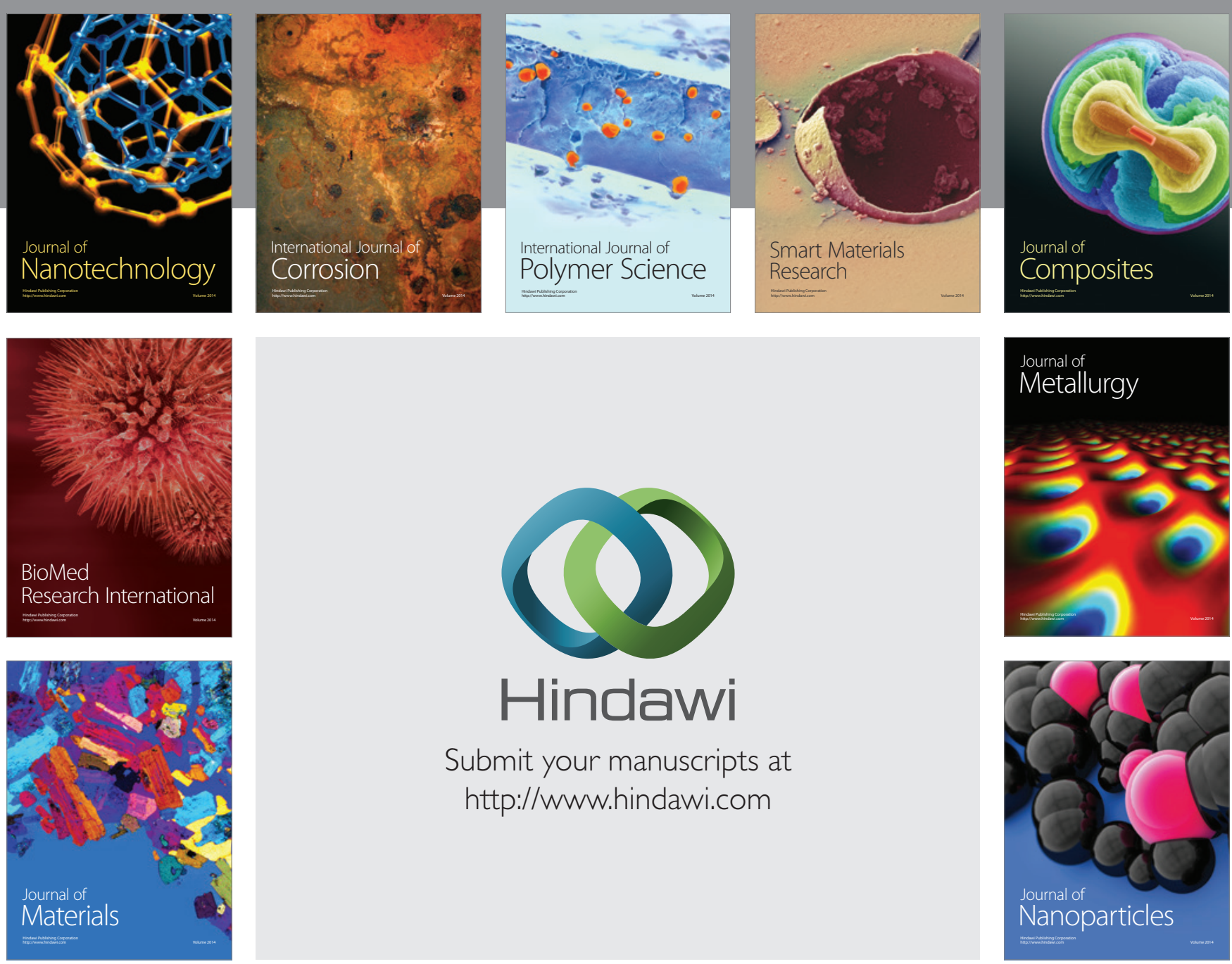

Submit your manuscripts at http://www.hindawi.com
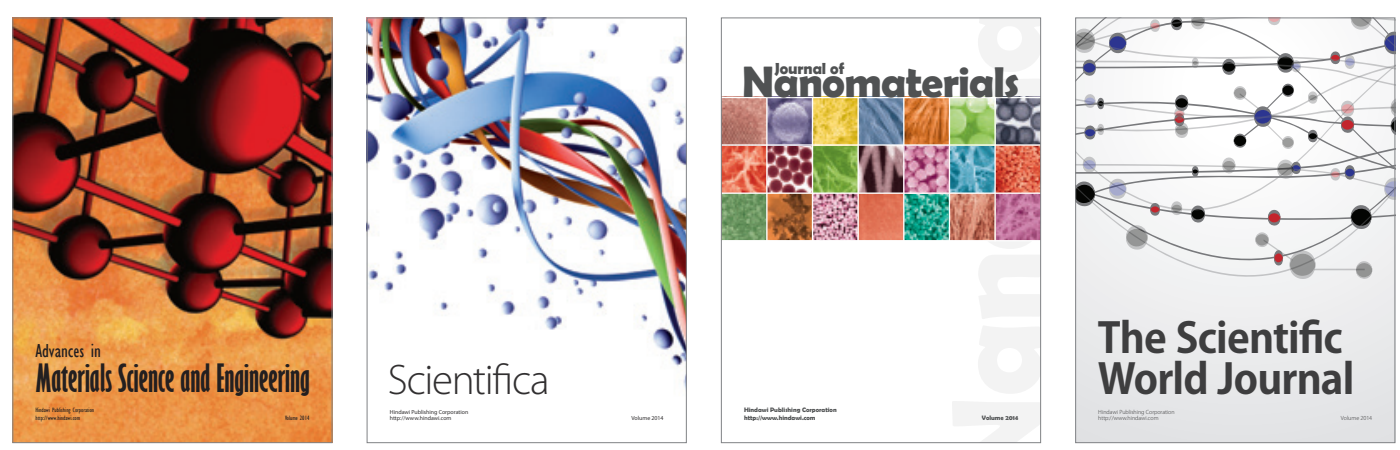

\section{The Scientific World Journal}
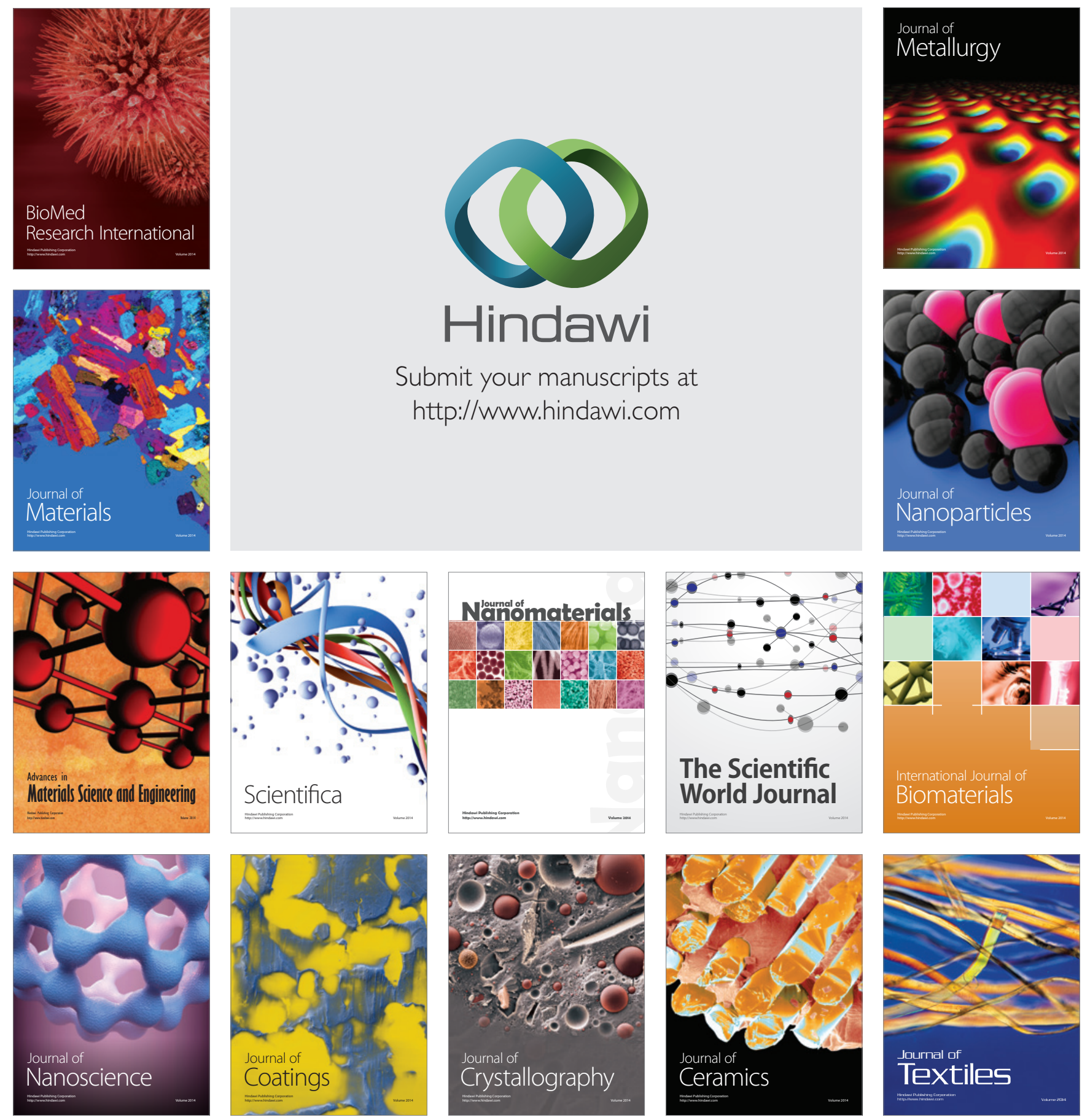